\title{
Does Shared Social Disadvantage Cause Black-Latino Political Commonality?
}

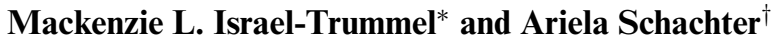

\begin{abstract}
Shared social disadvantage relative to Whites is assumed to motivate inter-minority political behavior but we lack causal evidence. Using a survey experiment of 1,200 African Americans, we prompt respondents to consider group social position when evaluating political commonality with Latinos. The experiment describes racial disparities in a randomized domain (education or housing), varies the description of inequality (either Black versus White, Latino versus White, or Black and Latino versus White), and offers half of the respondents a political cue to test whether shared social disadvantage causes Blacks' perceptions of political commonality with Latinos. We find little evidence of a causal relationship. We conclude that cross-racial minority political coalitions may be more difficult to activate than previously thought.
\end{abstract}

Keywords: survey experiment, race, Black politics, political commonality, minority coalitions

The United States will be a majority-minority nation by 2043, and Latinos are already the largest minority group (United States Census 2012). Latino population growth has been especially pronounced in places where Blacks reside

We are grateful to Gary Segura for all of his help and support in pursuit of this project. We thank the participants at the 2016 Western Political Science Association meeting and the 2015 Midwest Political Science Association meeting for their helpful feedback. We are grateful to David Rudd Ross for his careful reading. We are thankful for the helpful feedback provided by the anonymous reviewers. We thank the Graduate Research Opportunity Fund at Stanford University and the Office of the Vice President for Research at the University of Oklahoma for providing funding for this project. This material is also based upon work supported by the National Science Foundation under Grant No. SES1434303. Any opinions, findings, and conclusions or recommendations expressed in this material are those of the authors and do not necessarily reflect the views of the National Science Foundation. The data, code, and any additional materials required to replicate all analyses in this article are available at the Journal of Experimental Political Science Dataverse within the Harvard Dataverse Network, at: doi:10.7910/DVN/E3ZSRO. Neither author has any conflicts of interest.

*Department of Political Science, University of Oklahoma, 455 W. Lindsey, Norman, OK 73019, USA, e-mail: mackisr@ou.edu Twitter:@DrMackIT

${ }^{\dagger}$ Department of Sociology, Washington University in St. Louis, One Brookings Drive, St. Louis, MO 63130, USA, e-mail: ariela@wustl.edu Twitter:@ArielaSchachter

(c) The Experimental Research Section of the American Political Science Association 2018 
(Iceland 2009). Understanding how African Americans ${ }^{1}$ view the growing Latino population, and how this affects political behavior, is vital.

Scholars have alternately argued that shared social disadvantage causes or impedes political commonality between the two groups, in turn either fostering or hindering cooperation. Yet, most research relies on qualitative or observational data and has been unable to test whether there is a causal link, or specify the mechanism. Using survey experimentation on a national sample of African Americans, we test whether messages about social disadvantage promote a sense of shared political interests with Latinos.

We uncover null effects. Despite strong cross-sectional findings, there is not an immediate causal relationship between shared social disadvantage and African Americans' relatively high political commonality with Latinos. Rather, the causal link between social inequality and cross-racial political commonality is more contingent and limited than previous research suggests.

\section{COOPERATION OR CONFLICT?}

Although by most measures Blacks are the most disadvantaged group in the United States, Latinos face economic, social, and political hurdles that result in similarly disadvantaged outcomes (Telles and Ortiz 2008). Theories of political conflict and cooperation among minority groups rely on this shared social disadvantage. The competition framework posits that members of disadvantaged racial/ethnic groups are likely to see their interests as competing (Bobo and Hutchings 1996, Olzak 1992); arguments for political cooperation assume that shared social disadvantage increases perceptions of commonality, leading to coalitions (Kaufmann 2003). At the heart of this debate is whether Blacks' disadvantaged social position will lead them to view Latinos as allies facing similar circumstances, or competitors for meager resources and power.

The existing empirical evidence is mixed. On the one hand, multiple studies find that Blacks and Latinos perceive that they are in competition with one another, leading to political conflict (Gay 2006, Kaufmann 2007, McClain and Karnig 1990, McClain et al. 2006, Sonenshein 2003). In many cities, rather than forming coalitions African Americans (Latinos) have defected from Democratic Latino (African American) candidates (Barreto 2004, Kaufmann 2003). However, among national elites there is little evidence of competition (Hero and Preuhs 2013, Williams and Hannon 2016) and even findings of coalition building (Tyson 2016). At the mass level, while there may be "cracks in the rainbow," there is still cross-racial electoral cooperation (Kaufmann 2003). In sum, Blacks and Latinos have historically both cooperated and competed within the political realm, and

\footnotetext{
${ }^{1}$ We use the terms Black and African American interchangeably throughout this article. The survey used respondents' preferred term.
} 
both outcomes are thought to be driven by the groups' shared social disadvantage relative to Whites.

\section{POLITICAL COMMONALITY}

Research on inter-minority political cooperation builds on linked fate-the sense that one's fate is connected to the fate of their racial group (Dawson 1994, Tate 1993) - to connect perceptions of political commonality between communities of color with common (social) struggles (Kaufmann 2003, McClain et al. 2006, Sanchez 2008). Despite the prevalence of this logic in scholarship on inter-minority cooperation, we know of no studies that have tested whether perceptions of shared social disadvantage cause attitudes about inter-group political commonality. In part, the lack of causal research is due to the impossibility of randomizing social position. Previous research on this topic relies on creative analysis of observational data for theory-building and testing.

However, highlighting social inequality prior to measuring political commonality with Latinos should make social inequality more relevant to respondents' calculations about commonality, as frames emphasize particular considerations to affect how individuals form preferences (Druckman 2011, Iyengar and Kinder 1987, Zaller 1992, Zaller and Feldman 1992). While we may not offer new information - the realities of racial disadvantage may be all too familiar - by varying how inequality is framed, we can test whether the theoretical causal link between social disadvantage and commonality holds. This paper provides the first rigorous test of this theoretical mechanism for the production of Black-Latino political commonality.

\section{HYPOTHESES}

Frames that emphasize shared Black-Latino inequality relative to Whites should promote political commonality with Latinos, compared to frames that emphasize comparisons between Blacks and Whites or Latinos and Whites, if the mechanism for building political commonality is a shared social disadvantage:

$\mathrm{H}_{1}$ : Framing racial inequality as Black and Latino shared inequality compared to Whites should boost perceived commonality with Latinos.

Panethnicity and linked fate among Latinos can form a basis for commonality with African Americans (Kaufmann 2003, Sanchez 2008). We similarly expect racial linked fate will be correlated with perceptions of cross-racial political commonality:

$\mathrm{H}_{2}$ : Linked fate should be positively associated with Latino commonality independent of treatments. 
Most research assumes that social conditions translate into political beliefs about shared position and interests (Gay 2006, Kaufmann 2003). However, citizens are often unable to form political attitudes based on economic conditions, particularly when race is salient (Huckfeldt and Kohfield 1989, Key 1949, Roediger 1992). Respondents might require an explicitly political message to connect their shared social position to political commonality:

$\mathrm{H}_{3}$ : Political messages should amplify the expected effects of racial frames.

\section{DATA AND EXPERIMENTAL ANALYSIS}

To test our hypotheses, we fielded a survey in Winter 2016 with 1,200 African Americans (Israel-Trummel and Schachter 2018). ${ }^{2}$ Our sample was drawn from Survey Sampling International's (SSI) online panel and was quota sampled to meet current population survey (CPS) estimates for the Black population with respect to gender, age, education, and census region.

The experiment is a $4 \times 2 \times 2$ design. First, respondents were randomized into one of the four groups. Three of the treatment groups received an abbreviated news article that varied how inequality was described: Blacks versus Whites, Latinos versus Whites, or Blacks and Latinos versus Whites (see the online Appendix for treatments). The fourth group received a placebo. This design is a form of an emphasis frame, where different dimensions of a political problem are emphasized, and each could potentially shape attitudes on the outcome variable (Druckman 2011). The second randomization decided whether the article focused on either housing or education. The final randomization offered a political message to half the respondents. Respondents who received the political treatment were told at the end of the article: "Experts predict that [the future of education reform/access to home loans] will depend on the results of the 2016 elections, with the Republican and Democratic parties expected to present competing proposals." Following the treatment manipulations, respondents were asked about their perceptions of political commonality with Latinos. ${ }^{3}$ Latino commonality ranges from 1 (Nothing in common) to 4 (A lot in common).

\section{RESULTS}

We first compare the main effects of the treatments relative to the placebo, pooling across the domain (housing or education). Figure 1 shows the lack of any

\footnotetext{
${ }^{2}$ SSI collected 1,200 complete responses to the entire survey. We have more than 1,200 respondents who completed at least the treatment that we analyze in this survey, as there were break-offs further down the survey after our experiment.

${ }^{3}$ The exact wording of the question asked: Thinking about government services, political power, and representation, how much do blacks/African-Americans have in common with other racial groups in the United States today? Respondents were asked, in random order, about commonality with Latinos and Whites. This measure comes from the 2006 Latino National Survey (http://www.icpsr.umich.edu/ icpsrweb/DSDR/studies/20862).
} 


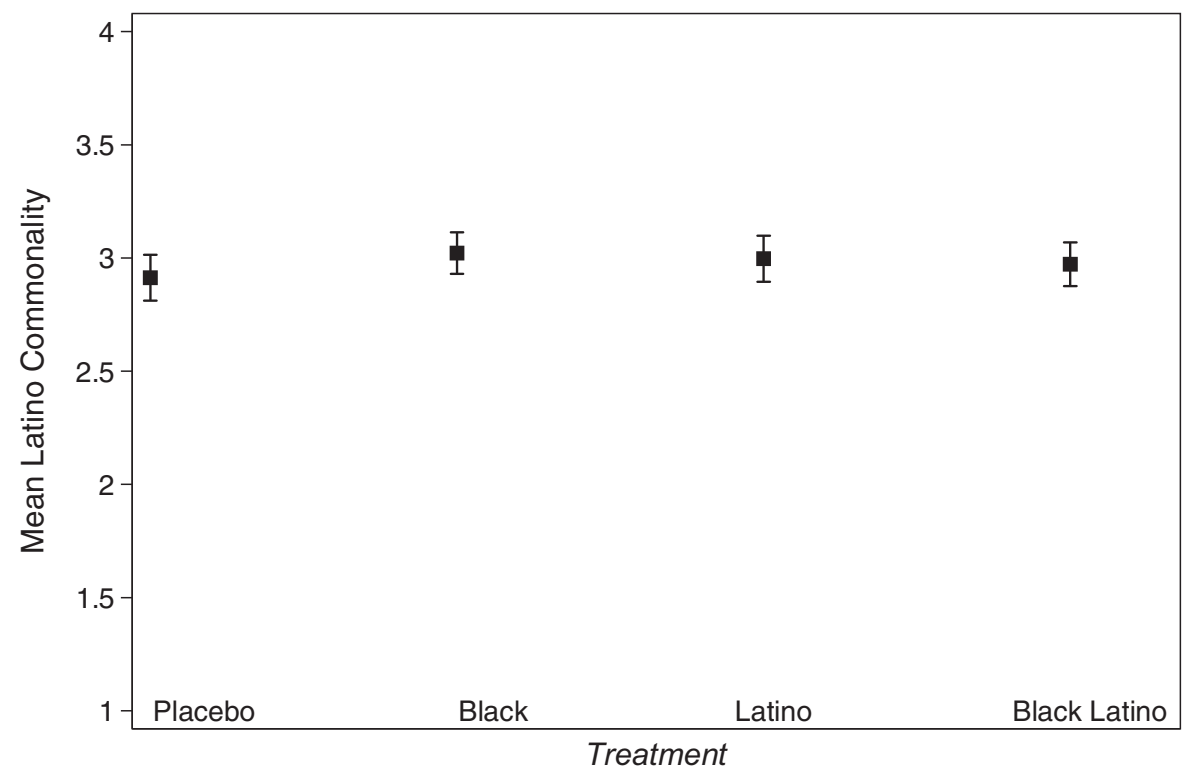

Figure 1

Treatment Effects on Latino Political Commonality.

significant differences. This is somewhat surprising as respondents in the BlackLatino condition received a specific message emphasizing shared Black-Latino social disadvantage. In the aggregate, it appears that framing social commonality fails to increase African Americans' perceptions of political commonality with Latinos. ${ }^{4}$ Adding further confidence to our null finding, in Table 1 we estimate the treatment effects on Latino commonality using OLS, controlling for respondent characteristics (Gerber and Green 2012). These models confirm our null findings. ${ }^{5}$ The effect for each treatment is positive, but none reach statistical significance.

\footnotetext{
${ }^{4}$ With any null effect, the concern is whether the treatment was received. In a pretest of our experiment on Black MechanicalTurk respondents, we asked respondents whether they supported a tax increase to address educational inequality, as we anticipate that those who are told about inequality will be more supportive of tax increases to address inequality than respondents in the placebo condition. Treated respondents were between 19 and 27 percentage points more supportive than those in the placebo. We included the same manipulation check in the SSI study but the differences were no longer significant. We ran an additional manipulation check on Black MechanicalTurk respondents from December 9 to December 11, 2017, to test whether respondents were attentive. We find high levels of attentiveness ( $83.33 \%$ of respondents in the placebo and $92.05 \%$ of respondents in the treatment). Please see the online Appendix for detailed information on manipulation checks.

${ }^{5}$ We also examined whether the treatments shaped political commonality with Whites. If social positioning were the foundation for perceptions of political commonality, we should expect that these racial treatments would be associated with decreased perceptions of political commonality with Whites. However, there is no significant relationship.
} 


\section{Table 1}

OLS Estimates of Treatment Effects on Latino Political Commonality, Coefficients and (SEs)

(1)

(2)

(3)

All cases

All cases

Education

Housing

$\begin{array}{lc}\text { Race treatment } & \\ \text { Placebo (ref) } & \\ \text { Black } & 0.113 \\ & (0.071) \\ \text { Latino } & 0.089 \\ & (0.071) \\ \text { Black and Latino } & 0.063 \\ & (0.070) \\ \text { Political message treatment } & \\ \text { Non-political (ref) } & \\ \text { Political } & 0.024 \\ & (0.050)\end{array}$

Race by political message treatments

Placebo, non-political (ref)

Placebo, political

0.113

0.089

0.063

$(0.050)$

Black, non-political

Black, political

Latino, non-political

0.084

$-0.011$

0.194

(0.100)

(0.133)

$(0.151)$

0.157

0.086

$0.241^{\dagger}$

(0.098)

(0.136)

$(0.143)$

0.150

0.101

0.209

$(0.101)$

(0.137)

$(0.150)$

0.084

0.086

0.096

$(0.100)$

(0.136)

$(0.145)$

Latino, political

$0.180^{\dagger}$

0.082

$0.286^{*}$

$(0.100)$

(0.141)

(0.144)

Black and Latino, non-political

0.144

$-0.014$

$0.314^{*}$

$(0.100)$

(0.137)

$(0.148)$

Black and Latino, political

0.069

$-0.121$

$0.263^{\dagger}$

(0.098)

(0.135)

$(0.143)$

Domain treatment

Education (ref)

Housing

-0.076
$(0.050)$
$2.936^{*}$
$(0.060)$
0.004
1300

(0.050)

$2.907^{*}$

$2.989^{*}$

$2.737^{*}$

Constant

(0.074)

(0.094)

$(0.105)$

$R$-squared

0.005

0.007

0.011

$N$

1300

654

$* p<0.05$

${ }^{\dagger} p<0.10$.

While the treatments have no main effect on political commonality with Latinos, it is possible that there are heterogeneous treatment effects. Given the relationship between linked fate and commonality, we test whether linked fate moderates the treatments. The lack of significant interaction between linked fate and the experimental treatments clarifies previous observational analysis. While African Americans with higher racial linked fate are more likely to express commonality with Latinos $\left(\mathrm{H}_{2}\right)$, they are no more likely to respond to messages about shared 
inequality. Instead those who feel more linked to their own group are also more likely to believe their interests are similar to another minority group. ${ }^{6}$

The analysis indicates that perceptions of shared social conditions are not the mechanism for building political commonality. Next, we test whether shared social position needs to be explicitly tied to politics. In brief, we find no support for the political mechanism within the educational domain, and limited evidence with housing.

Pooling across the inequality domains we find no difference comparing those who were told that experts expect the 2016 election to affect their issue versus those who did not receive a political message (Figure 2). Table 1 disaggregates the domains. These models confirm the null result for the pooled analysis and for education alone. However, within the housing domain, both Black-Latino conditions increase commonality ( $p=0.066$ political, $p=0.034$ non-political), and the political Latino treatment boosts commonality relative to the non-political placebo ( $p=$ 0.047). Within the domain of housing access, providing information about Latino inequality relative to White, coupled with a political cue, can promote a sense of shared political interests with Latinos. In total, these results provide qualified support for $\mathrm{H}_{3}$. A political message, coupled with a racial frame about housing that references Latino inequality, promotes a sense of political commonality with Latinos. However, providing a political cue in the educational inequality domain does not affect Latino political commonality.

\section{DISCUSSION AND CONCLUSION}

Our results do not support the theory that shared social disadvantage is the causal mechanism for creating political commonality. There is no evidence that shared educational disadvantage promotes commonality, and very limited support for the mechanism within the domain of housing inequality, if shared disadvantage is coupled with a political message. We confirm the correlation between racial linked fate and Latino commonality, but our findings suggest that the mechanism of shared disadvantage (alone) between Blacks and Latinos is insufficient.

We are confident that we have identified a true null effect. Although pretreatment (in our case, real experiences of social disadvantage) is a threat to survey experiments (see Gaines, Kuklinski and Quirk 2007), individuals have multiple considerations that they could bring to bear on any issue; providing respondents with information emphasizing one of those considerations should encourage them to draw more heavily on that particular consideration (Zaller 1992, Zaller and Feldman 1992). To test whether pretreatment could be limiting our results, we ran an additional survey of 178 Black respondents on MechanicalTurk in December 2017 comparing only the Black-Latino housing treatment versus the placebo.

${ }^{6}$ For analysis of potential moderators, see the online Appendix. 


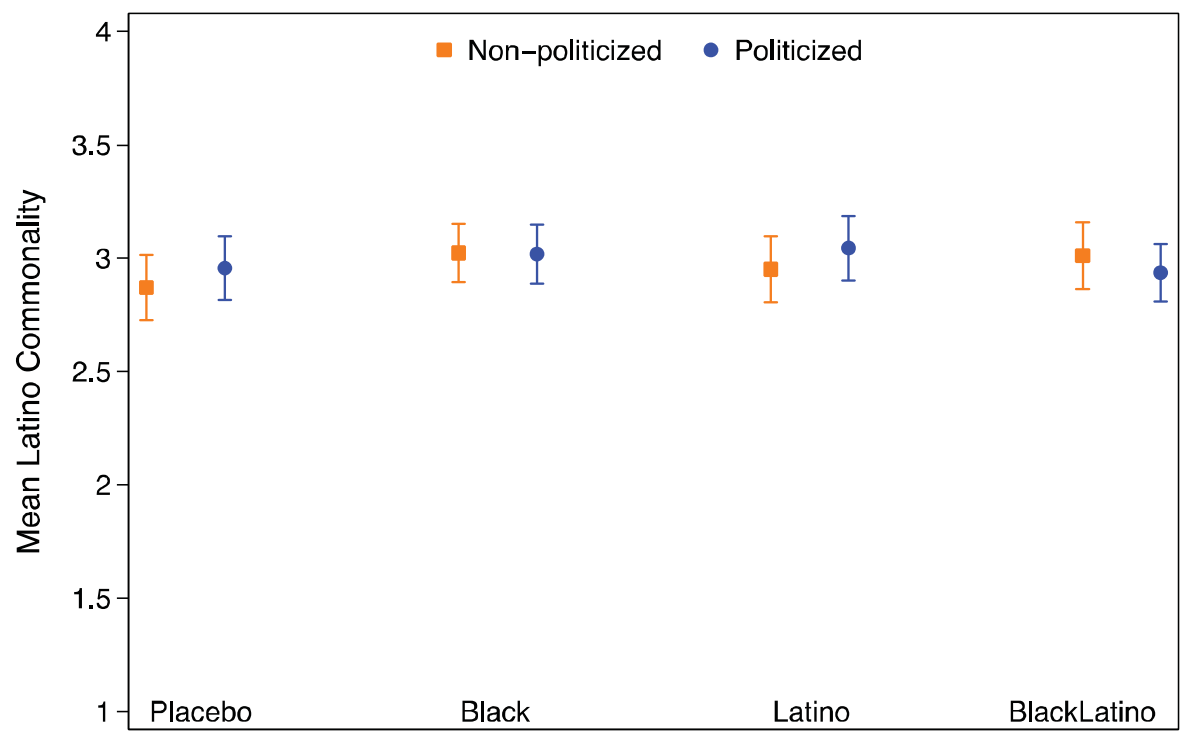

Figure 2

Political Messages and Treatment Effects on Latino Political Commonality. (Color online)

Although we find that there is high knowledge overall about inequality, treated respondents are significantly more likely to believe that Black and Latino borrowers tend to be given higher-priced mortgages than Whites $(p=0.03)$. Another measure of pretreatment (that Black and Latino borrowers tend to receive less coaching on mortgage borrowing) fails to achieve statistical difference between the treatment and placebo, but is in the correct direction $(p=0.16)$. Finally, we offer another true statement (whether Black and Latino borrowers are more likely to own homes in disadvantaged neighborhoods compared to Whites) that was not mentioned in the treatment article. We find no difference between beliefs about the accuracy of this statement comparing placebo and treatment conditions on this measure $(p=0.45)$, suggesting that our treatments did move beliefs about inequality as described in the article, and pretreatment cannot fully account for our null results. In addition, if pretreatment were driving our results, we would expect Blacks living in areas with low-exposure to Latinos (e.g., lower percent Latino zip-codes and low-immigration states) to demonstrate stronger treatment effects relative to those with more exposure (and thus more pretreatment). However, we find no differences in treatment effects by exposure to Latinos. Finally, while pretreatment is always a concern, research on Whites shows that race can be framed and primed despite the historic, institutional, and structural realities of race (Mendelberg 2001, Valentino et al. 2002). Researchers should not simply assume that race cannot be experimentally tested on minority samples. 
Our results indicate that a commonly assumed mechanism for building crossracial minority cooperation is likely insufficient. Scholars need to theorize what other mechanisms could be driving group commonality. We hope that our findings will spur further causal research on minority political behavior. As the United States marches closer to majority-minority status, understanding the forces that shape inter-minority politics will only increase in importance.

\section{SUPPLEMENTARY MATERIAL}

To view supplementary material for this article, please visit https://doi.org/ 10.1017/XPS.2018.15

\section{REFERENCES}

Barreto, Matt A. 2004. "Si Se Puede! Latino Candidates and the Mobilization of Latino Voters." American Political Science Review 101(3): 425-41.

Bobo, Lawrence and Vincent L. Hutchings. 1996. "Perceptions of Social Group Competition: Extending Blumer's Theory of Group Position to a Multiracial Social Context." American Sociological Review 61: 951-72.

Dawson, Michael C. 1994. Behind the Mule: Race and Class in African American Politics. Princeton: Princeton University Press.

Druckman, James N. 2011. "What's It All About?: Framing in Political Science." In Perspectives on Framing, ed. Gideon Keren. New York: Psychology Press. pp. 279-301.

Gaines, Brian J., James H. Kuklinski, and Paul J. Quirk. 2007. "The Logic of the Survey Experiment Reexamined." Political Analysis 15: 1-20.

Gay, Claudine. 2006. "Seeing Difference: The Effect of Economic Disparity on Black Attitudes toward Latinos." American Journal of Political Science 50(4): 982-97.

Gerber, Alan S. and Donald P. Green. 2012. Field Experiments: Design, Analysis, and Interpretation. New York: WW Norton.

Hero, Rodney E. and Robert R. Preuhs. 2013. Black-Latino Relations in U.S. National Politics: Beyond Conflict or Cooperation. New York: Cambridge University Press.

Huckfeldt, Robert and Carol Weitzel Kohfeld. 1989. Race and the Decline of Class in American Politics. Urbana; Chicago: University of Illinois Press.

Iceland, John. 2009. Where We Live Now: Immigration and Race in the United States. Berkeley: University of California Press.

Israel-Trummel, Mackenzie and Ariela Schachter. 2018. "Replication Data for: Does Shared Social Disadvantage Cause Black-Latino Political Commonality?" Harvard Dataverse, V1. doi:10.7910/DVN/E3ZSRO.

Iyengar, Shanto and Donald R. Kinder. 1987. News That Matters: Television \& American Opinion. Chicago: University of Chicago Press.

Kaufmann, Karen M. 2003. "Cracks in the Rainbow: Group Commonality as a Basis for Latino and African American Political Coalitions." Political Research Quarterly 56(2): 199-210.

Kaufmann, Karen M. 2007. "Immigration and the Future of Black Power in U.S. Cities." Du Bois Review 4(1): 79-96. 
Key, V.O. 1949. Southern Politics in State and Nation. Knoxville, TN: University of Tennessee Press.

McClain, Paula D. and Albert K. Karnig. 1990. "Black and Hispanic Socioeconomic and Political Competition." American Political Science Review 84: 535-45.

McClain, Paula D., Niambi M. Carter, Victoria M. DeFrancesco Soto, Monique L. Lyle, Jeffrey D. Grynaviski, Shayla C. Nunnally, Thomas J. Scotto, J. Alan Kendrick, Gerald F. Lackey, and Kendra Davenport Cotton. 2006. "Racial Distancing in a Southern City: Latino Immigrants' Views of Black Americans.” Journal of Politics 68(3): 571-84.

Mendelberg, Tali. 2001. The Race Card: Campaign Strategy, Implicit Messages, and the Norm of Equality. Princeton, NJ: Princeton University Press.

Olzak, Susan. 1992. The Dynamics of Ethnic Competition. Stanford, CA: Stanford University Press.

Roediger, David R. 1992. The Wages of Whiteness: Race and the Making of the American Working Class. New York: Verso.

Sanchez, Gabriel. 2008. "Latino Group Consciousness and Perceptions of Commonality with African Americans." Social Science Quarterly 89(2): 428-44.

Sonenshein, Raphael J. 2003. "The Prospects for Multiracial Coalitions: Lessons from America's Largest Cities." In Racial Politics in American Cities, eds. Rufus P. Browning, Dale Rogers Marshall, and David H. Tabb. New York: Longman. pp. 51-76.

Tate, Katherine. 1993. From Protest to Politics: The New Black Voters in American Elections. New York: Russell Sage Foundation.

Telles, Edward E. and Vilma Ortiz. 2008. Generations of Exclusion: Mexican Americans, Assimilation, and Race. New York: Russell Sage Foundation.

Tyson, Vanessa. 2016. Twists of Fate: Multiracial Coalitions and Minority Representation in the U.S. House of Representatives. New York: Oxford University Press.

United States Census. 2012. "U.S. Census Bureau projections show a slower growing, older, more diverse nation a half century from now." Washington, D.C.: U.S. Census Bureau Newsroom Archive. https://www.census.gov/newsroom/releases/archives/population/ cb12-243.html.

Valentino, Nicholas A., Vincent L. Hutchings, and Ismail K. White. 2002. "Cues that Matter: How Political Ads Prime Racial Attitudes During Campaigns." American Political Science Review 96(1): 75-90.

Williams, Kim M. and Lonnie Hannon. 2016. "Immigrant Rights in a Deep South City: the Effects of Anti-Immigrant Legislation on Black Elite Opinion in Birmingham, Alabama." Du Bois Review 13(1): 139-57.

Zaller, John R. 1992. The Nature and Origins of Mass Opinions. New York: Cambridge University Press.

Zaller, John and Stanley Feldman. 1992. "A Simple Theory of the Survey Response: Answering Questions versus Revealing Preferences." American Journal of Political Science 36(3): 579-616. 